\title{
Una apuesta moral por alcanzar calidad en el tratamiento informativo del dolor ${ }^{1}$
}

Germán Ortiz-Leiva²

Recibido: 2016-07-28

Enviado a pares: 2016-07-29
Aprobado por pares: 2016-08-31

Aceptado: 2016-11-16

DOI: 10.5294/pacla.2018.21.1.7

Para citar este artículo / to reference this article / para citar este artigo

Ortiz-Leiva, G. (2018). Una apuesta moral por alcanzar calidad en el tratamiento informativo del dolor. Palabra Clave, 21(1), 134-164. DOI: 10.5294/pacla.2018.21.1.7

\section{Resumen}

Este artículo tiene como objeto resaltar el sello moral de la labor del reportero para mejorar la calidad del relato elaborado en el momento de cubrir acontecimientos que conllevan algún tipo de desconsuelo y pena en torno a las víctimas que allí se producen. El camino a seguir parte de los valores interpretativos que requiere el periodista marcados por la necesidad de entender las razones que antecedieron las acciones no solo humanas, sino naturales, finalmente objeto de la mayor atención informativa, sobre todo, en tales hechos de dolor. Entre estos valores, se destacan el respeto que le permite al reportero acceder a una mejor consciencia de sí mismo ante otros que como él pueden ser objeto de informaciones angustiosas, la solidaridad que posibilita compartir con las informaciones emitidas, sentimientos y frustraciones y la confianza que dispone la situación informati-

1 Este texto es el resultado de una reflexión teórica y conceptual, elaborado en un grupo de trabajo sobre problemas morales, éticos y de responsabilidad social. La línea a la que está adscrito tiene como objetivo entender los valores que ejercen los reporteros a la hora de cubrir los hechos informativos. Esta preocupación permite indagar no solo sobre temas de calidad informativa, sino también sobre las llamadas culturas profesionales que profesan los periodistas e incluso sobre su libertad de expresión de gran interés para entender diversos fenómenos de opinión pública. Se complementa, de esta manera, un trabajo académico interdisciplinario en la Escuela de Ciencias Humanas con el apoyo de la Dirección de Investigación de la Universidad del Rosario.

2 orcid.org/0000-0001-8208-3169. Universidad del Rosario, Colombia. german.ortiz@urosario.edu.co 
va compleja para ser tratada con el mayor cuidado y discreción. En últimas, el cubrimiento periodístico en situaciones de duelo bajo esta estimación proporciona una variación o transformación de la noticia respecto de la calidad del tratamiento del dolor, ya que, aunque las víctimas son siempre objeto del mayor interés informativo, no siempre se logra calidad en los términos más adecuados a su propia vulnerabilidad. Así, la calidad de la información periodística se presentará como una transformación del acto informativo en relación con la búsqueda, la elaboración y la difusión de relatos de dolor y muerte, ligada en el proceso por la acción propia de lo que hace el periodista y la noción de valor agregado sobre lo que informa.

\section{Palabras clave}

Calidad informativa; transformación informativa; respeto; solidaridad; confianza; razones morales (Fuente: Tesauro de la Unesco). 


\section{A Moral Bet on Achieving Quality in the Informative Handling of Grief}

\section{Abstract}

The purpose of this paper is to highlight the moral nature of the reporter's work in order to improve the quality of the story when covering events that involve some kind of grief and sorrow for the victims. The solution starts from the interpretive values that are required from the reporter, marked by the need to understand the reasons preceding human and natural actions, which are finally subject to the greatest media attention, particularly in such painful acts. Among these values, we highlight the respect that allows reporters to access a better self-awareness before others who, like him, can be the object of distressing information, the solidarity that makes it possible to share with the information given, the feelings and frustrations, and the trust that the complex informative situation will be treated with the greatest care and discretion. Ultimately, the journalistic coverage in situations of grief provides a variation or transformation of the news regarding the quality of the handling of grief, because, although victims are always the object of greater informative interest, quality is not always achieved in the most appropriate terms according to their own vulnerability. Thus, the quality of the journalistic information will be presented as a transformation of the informative related to the search, elaboration and dissemination of stories of grief and death, linked in the process by the very action of what the reporter does and the notion of added value about what is being reported.

\section{Keywords}

Informative quality; informative transformation; respect; solidarity; trust; moral reasons (Source: Unesco Thesaurus). 


\section{Uma aposta moral por alcançar qualidade no tratamento informativo da dor}

\section{Resumo}

O trabalho a seguir tem como objeto destacar o selo moral do trabalho de repórter para melhorar a qualidade do relato elaborado no momento de cobrir acontecimentos que implicam algum tipo de desconsolo e pena com relação às vítimas que ali se produzem. $\mathrm{O}$ caminho a seguir parte dos valores interpretativos requeridos pelo jornalista e marcados pela necessidade de entender as razões que antecederam as ações não somente humanas, mas também naturais, que finalmente são alvo da maior atenção informativa, sobre tudo em tais fatos de dor. Entre estes valores, se destacam o respeito que permite ao repórter o acesso a uma melhor consciência de si mesmo perante outros que como ele, podem ser alvo de informações angustiosas, a solidariedade que permite compartilhar as informações emitidas, sentimentos e frustrações e a confiança que dispõe a situação informativa complexa para ser tratada com o maior cuidado e descrição. Finalmente, a cobertura jornalística em situações de dor sob esta estimativa proporciona uma variação ou transformação da notícia em relação à qualidade do tratamento da dor, já que, ainda que as vítimas sejam sempre objeto de maior interesse informativo, nem sempre se obtém qualidade nos termos mais adequados à sua própria vulnerabilidade. Assim, a qualidade da informação jornalística se apresentará como uma transformação do ato informativo com relação à busca, a elaboração e a difusão de relatos de dor e morte, ligada no processo pela ação própria do jornalista e a noção de valor agregado sobre o que este informa.

\section{Palavras-chave}

Qualidade informativa; transformação informativa; respeito; solidariedade; confiança; razões morais (Fonte: Tesauro da Unesco). 


\section{A manera de introducción: ¿por qué informar sobre asuntos de dolor?}

Las informaciones periodísticas sobre hechos dolorosos desencadenan sentimientos dispares en los ciudadanos. Por un lado, pueden generar pesar y compasión hacia las personas y víctimas involucradas; por otro, indiferencia e incluso mofa si los afectados son odiados o se les responsabiliza de lo que padecen. En todo caso, tales notas ocupan una parte importante de la prensa y los noticieros de radio y televisión. Incluso, han llevado a la creación de diarios vespertinos de alto tiraje que se caracterizan por hacer hincapié en la denominada crónica judicial o "roja" bajo el tratamiento informativo abiertamente sensacionalista que sobredimensiona los hechos, no solo por la naturaleza que demanda, sino por la crudeza de los detalles descritos.

El texto que sigue atiende objetivamente a inquietudes relacionadas con el asunto de la calidad informativa sobre estos eventos que soportan dolor físico o moral bajo circunstancias y consecuencias diversas. Dicha calidad entendida, en todo caso, como algo que trasciende el orden técnico y formal del producto periodístico para asumirse más bien como la posibilidad de variación, cambio o transformación de la información periodística en el momento de su difusión para reconocimiento público. ${ }^{3}$

La propuesta enuncia la necesidad de contar, desde el hacer periodístico, ${ }^{4}$ con un rasgo moral (valores o razones), que matice la intención del reportero y marque sus rutinas de trabajo como parte de este para comunicar hechos que acontecieron sobre dolor y muerte. En este sentido, $\mathrm{y}$ desde otros escenarios, algunos autores insisten en que tanto medios de

3 "Los campos semánticos a los que se aplica la palabra dolor son muy variados. El más evidente es el llamado dolor físico: un golpe, una quemadura, un resfriado causan la reacción de rechazo en el cuerpo, una molestia" (Aranguren, 2002, s. p.). Así, el dolor es un medio de adaptación por el que el ser humano facilita su supervivencia. El dolor moral, en cambio, es más complicado de asumir. La desaparición de un ser querido, por ejemplo, se convierte en una experiencia significativa que nos lleva a sentir tristeza y soledad. Una desazón que nos acompaña subjetivamente y, por tanto, envuelve al cuerpo mismo, para ponernos en una condición de desesperanza frente a todo lo que nos rodea.

4 El periodismo es un hacer intelectual, moral y práctico, enmarcado bajo la praxis de interpretar lo que acontece en el entorno para darle sentido propio y social al presente. Dicha praxis pone de relieve su dimensión ética, que se orienta, fundamentalmente, a comunicar los hechos que les permitan a los ciudadanos mejorar la toma de decisiones en comunidad. 
comunicación como empresas informativas adopten posturas que permitan una adhesión social amplia a los derechos fundamentales, a la vez que una clara exigencia de respetar la libertad de las audiencias respecto de sus propios ideales, creencias, inquietudes e, incluso, razones. ${ }^{5}$

Es de advertir, igualmente, que no se trata de imponer determinados valores de reconocimiento universal hacia y desde los medios de información. Sí, en cambio, invitar a una reflexión sin mayores matices de pretensión, sobre la posibilidad de mejorar la calidad informativa de la prensa desde un ámbito moral en los sucesos noticiosos que se desprenden de situaciones complejas, en ocasiones contradictorias y por demás difíciles de tratar desde el periodismo y comprender por cuenta de un creciente interés ciudadano. ${ }^{6}$

\section{Los valores en la labor del reportero ${ }^{7}$}

Si se pudieran categorizar bajo algún sentido los valores que regularmente la prensa asume en el momento de cubrir un hecho, se puede advertir una primera distinción hacia un tipo específico que podría denominarse valores metodológicos o procedimentales, los cuales ayudan a editores y reporteros a construir mejor sus relatos periodísticos respecto de una calidad que fue ampliamente reconocida luego de la publicación en la década de 1940 del informe final de la Commission on Freedom of the Press dirigida entonces por Robert M. Hutchins y Zechariah Chafee.

5 John Ralws lo expresa del siguiente modo: "Ha parecido acertado a muchos filósofos, y parece cosa de sentido común, el hecho de que distinguimos, como cuestión de principio, entre las pretensiones de la libertad y de lo justo, por un lado, y lo deseable de aumentar el beneficio social en conjunto, por otro; y que damos cierta prioridad, si no un valor absoluto, a lo primero. Se supone que cada miembro de la sociedad tiene una inviolabilidad fundada en la justicia, o como dicen algunos, en un derecho natural, el cual no puede ser anulado ni siquiera para el bienestar de cada uno de los demás. [... ] Por tanto, en una sociedad justa, las libertades básicas se dan por sentadas, y los derechos, asegurados por la justicia, no están sujetos al regateo político ni al cálculo de intereses sociales (1995, p. 57).

6 El dolor físico o moral es un asunto del que siempre habrá que informar por el significado que tiene para el hombre tanto de quien lo padece como de quien lo conoce (López Mañero, 1997).

7 Uno de los elementos que define la cultura periodística es la figura del reportero que marca el hacer mismo dentro de la profesión, sobre todo, porque, en últimas, será quien estará informando desde el lugar de los hechos; nuestro rol de interés a efectos del artículo. En tanto que la figura del periodista se asocia funcionalmente a quien labora con la información periodística. Por supuesto, finalmente, una y otra se entrelazarán bajo una sola tarea (Traquina, 2013). 
Entre lo más relevante de las conclusiones de la llamada Comisión Hutchins, está la reformulación del problema de la calidad en términos poco tratados para entonces. Según ella, hay amenazas a la libertad de expresión, porque es la prensa la que está en crisis. Se hace necesario estudiarla y proponerle cambios con otra mirada: "Es de la mayor importancia, entonces, que las medidas que efectivamente se puedan tomar, se tomen. El no hacerlo, implicaría que se establezca una preocupación seria y permanente sobre la relación moral entre la prensa y la sociedad” (Lecaros, 2014, p. 91).

Lo interesante es que tales recomendaciones advierten de la importancia de las razones morales en la deliberación práctica del hacer periodístico. Un asunto que demanda la relación con la sociedad a la que se le informa. Entre otras, no basta con que se le informe sobre un hecho, sino, sobre todo, que se haga sobre la verdad del hecho mismo. Además, una sensibilidad hacia las razones morales es una condición necesaria de la libertad y la responsabilidad moral y ética precisamente de quienes actúen; en este caso, los propios periodistas. ${ }^{8}$ La inconmensurabilidad de tales razones con las razones no morales concede a la elección el lugar central que demanda la responsabilidad moral, pero, al mismo tiempo, la mantiene vinculada a la racionalidad y evita su conversión en un acto irresponsable (Moya, 1997, p. 57).

Los valores procedimentales de la tarea de informar encierran aspectos diversos, como la precisión, la proporcionalidad, el contexto, la transparencia, la objetividad, el tono, la veracidad e incluso la legitimidad, todos rasgos metodológicos en la recolección y elaboración de relatos que inciden directamente en su misma calidad al perfeccionar la información de hechos y protagonistas sobre las realidades de las que se informa. ${ }^{9}$

8 En sentido estricto, lo ético y lo moral no se refieren a lo mismo. Por ejemplo, el concepto de persona que, en el contexto de la moral, no significa otra cosa más que el otro ser humano, o sea, el "objeto" de la moral, para la ética, la persona o el "individuo", representará no algo simplemente dado, sino un concepto que implica determinadas particularidades. Tales singularidades se ajustarán a la manera como se aspira a vivir según sea el derecho natural, la deontología, el consecuencialismo, la utilidad y el bien, entre otras. Esta ambivalencia, sin embargo, es la que en ocasiones permite — según la intención en el uso de los términos_ que se las trate indistintamente (Margalit, 2002).

9 Para la prensa y, en general, para cualquier medio de comunicación, la tarea de informar se hace sobre la base de entender adecuadamente la realidad del mundo físico y social en los formatos establecidos para ello y en los canales 
Una segunda distinción se inclina a categorizar los llamados valores interpretativos, marcados por la necesidad de entender las razones que antecedieron las acciones humanas, finalmente, objeto de la atención informativa, sobre todo, en hechos de dolor. Valga recordar que la prensa en general suele poner su atención en problemáticas surgidas en torno a hechos socialmente controvertibles.

Más allá de la pertinencia del método según el caso para recopilar información e informar, estas interpretaciones soportan consideraciones morales de carácter universal, como son la verdad, la justicia, la honestidad, la responsabilidad o el respeto, entre otras, las que, aunque no son privativas del oficio del reportero, sí demarcan un aspecto importante del cubrimiento informativo al tratar de comprender las intenciones, las razones, las consecuencias o los deberes del actuar humano en cualquier circunstancia, pese a que se matice en la descripción de los hechos con la vieja idea de que "los hechos hablan por sí solos", en un marcado empirismo que parecería dejar la interpretación de sus razones a un lado de los propios sucesos (Hanitzsch, 2007).

\section{Una crítica persistente}

En general, las informaciones periodísticas sobre hechos violentos o dolorosos que ponen en situación vulnerable la vida en todas sus dimensiones siempre conllevan críticas por cuenta de la opinión pública y de quienes ven en ellas una falta de consideración por las víctimas o la exacerbación de los ánimos de las personas involucradas.

Incluso, al tratarse de hechos violentos incomprensibles e indiscriminados, como sucede con la mayoría de los actos del terrorismo, desencadena recurrentes llamados de atención hacia la tarea de informar de la prensa a la que responsabilizan por la "propaganda" que resulta de la difusión de tales actos, los mensajes de sus autores e incluso la disposición del mensaje informativo para que a través de este se reconozca la crueldad de 
las intenciones o las proclamas ideológicas justificantes que podrían causar amedrentamiento social hacia quienes se dirigen. ${ }^{10}$

Cuestionamientos, por supuesto, nada recientes. Ya a finales del siglo XIX e inicios del XX, se hacían alusiones a la estrecha relación entre la difusión de la violencia y su exaltación. Incluso los criminólogos europeos trataron de establecer las posibles causas externas que explicaran la conducta criminal de los delincuentes a través de lo publicado por la prensa. Gabriel Tarde primero y Gustave Le Bon después pusieron en circulación las nociones de contagio e imitación. Tarde cita en uno de sus libros la frase siguiente que había hecho fortuna ya por aquella época: "Si las infecciones epidémicas se extienden con el aire o con el viento, las epidemias del crimen siguen la línea del telégrafo" (Soria, 1987, p. 32). Reclamamos decoro de la prensa al cubrir hechos violentos, pero requerimos imágenes escuetas y dolorosas para reconocer de lo que somos capaces de hacer a otros $y$, por tanto, necesitamos denunciar.

Difícilmente, se hubiera reconocido para la época la cruenta dimensión del uso de armas nucleares si no se hubieran difundido al mundo entero las imágenes de aquellas víctimas luego del ataque de Norteamérica a Japón o leídos los reportajes de George Weller un mes después de los hechos en abierta contraposición al Pentágono, en los que describía lo que encontró como testigo ocular del primer holocausto nuclear de la humanidad (Weller, 1945).

Al respecto, pensadoras como Susan Sontag consideran que la persona que está perennemente sorprendida por la existencia de la depravación, que se muestra desilusionada e incluso incrédula cuando se le presentan pruebas de lo que unos seres humanos son capaces de infligir a otros -en el sentido de crueldades horripilantes y directas — no han alcanzado la ma-

10 Aunque acaecido hace ya buen tiempo, emblemático fue el caso del secuestro de un avión que viajaba de Atenas hacia Londres en junio de 1985 al ser desviado a Beirut por los secuestradores chiitas. Dentro de lo profusamente divulgado por las cadenas más importantes de televisión de la época, sobresale su inusitado interés por transmitir las peticiones y amenazas de los autores del hecho hasta el punto de motivar, entonces, una reflexión de Paul Johnson (1985) en la revista Time, que llegó a calificar el hecho como una coproducción entre televisión y terrorismo: más importante que las pistolas o las bombas, las armas más poderosas de un terrorista son nuestras cámaras de televisión. 
durez moral o psicológica. En su alusión, demanda que, a partir de cierta edad, nadie tiene derecho a semejante ingenuidad $y$ superficialidad... a este grado de ignorancia o amnesia (Sontag, 2003, p. 133). ${ }^{11}$

Paradójicamente, ahora mismo un enorme archivo de imágenes que irrumpe en redes sociales hace más difícil mantener este género de informar con un cierto defecto moral. ¿ $\mathrm{H}$ Hasta dónde debemos permitir que las imágenes atroces nos persigan? Aunque solo se trate de muestras y no consigan apenas abarcar la mayor parte de la realidad a la que hacen referencia, cumplen, no obstante, una función esencial. Las imágenes dicen: esto es lo que los seres humanos se atreven a hacer, y quizá se ofrezcan a hacer, con entusiasmo, convencidos de que están en lo justo. Eso es lo que no se puede olvidar (p. 134).

El testimonio atroz del suceso en Markale a la posteridad quedó registrado bajo unas imágenes y relatos periodísticos a manera de un testimonio notable de memoria mediática. Su sentido alude a las narrativas resultantes de la gestión del pasado en los medios. Como objeto de reflexión, tratar la llamada memoria mediática conlleva cuestionar para bien o para mal cómo operan los medios en cuanto instancias que pretenden la vivificación y la actualización de la historia ante una determinada colectividad y a través de mecánicas de selección, negociación y circulación de valores.

En múltiples ocasiones, es el esfuerzo profesional de reporteros y editores quienes bajo situaciones de riesgo y en el centro de los conflictos

11 A propósito de lo anterior, es pertinente recordar situaciones acontecidas en la guerra de los Balcanes, como la del 5 de febrero de 1994 en contra de Sarajevo asediada por las fuerzas serbio-bosnias. A plena luz del día, y sin medir consecuencias, fue lanzado un proyectil de alto calibre contra un grupo de civiles inermes que se aglomeraban alrededor de la plaza Markale. El resultado no podía ser peor, 66 personas asesinadas y casi 200 heridas de gravedad. El caso fue ampliamente registrado en las portadas de los diarios del mundo entero. La inquietud poco tiempo después se concentró en evaluar las razones por las que los reporteros habían decidido hacer públicas estas imágenes que evidenciaban el horror sin condición ni límite alguno. El asunto en cuestión no era haber informado del hecho, sino la manera como se había llevado a cabo, no tanto por los contenidos descritos, como sí por los apoyos de imágenes que no escatimaban esfuerzos por mostrar detalles del acto macabro. Eran imágenes perturbadoras, y de eso se trataba sin duda. Reclutadas a la fuerza de lo acontecido, se confiaba en que ellas llamaran la atención, sobresaltaran y sorprendieran. Tal como lo indicaba el viejo lema publicitario de Paris Match, el peso de las palabras, la conmoción de las fotos (Sontag, 2003, p. 32). 
terminan por definir para la opinión pública lo que acontece y merece su atención, compromiso e interés. De lo contrario, sería imposible conectar el ayer con el presente y, en perspectiva, este con el futuro. Quizá para Sontag se le atribuye demasiado valor a la memoria y no el suficiente a la reflexión. Sin embargo, recordar es una acción moral, tiene un valor ético en y por sí mismo. A su vez la memoria es, dolorosamente, la única relación que podemos sostener con los muertos (2003, p. 134).

\section{¿Y del tema de la calidad?}

En su acepción fundamental, la calidad se define en su propio reconocimiento. En ocasiones, no es más que un registro de los atributos o las propiedades tangibles con que cuentan la mayoría de los objetos que se encuentran a nuestro alrededor y que nos permiten apreciarlos o valorarlos como de calidad en relación con otros similares. Por ejemplo, la calidad de una silla podría evidenciarse a partir de sus formas, colores, funcionalidades y otros detalles palpables que nos indican objetivamente el grado de calidad en mayor o menor grado en relación con otra igual o similar a la que se compara para poder afirmar que esta es de mejor calidad que aquella.

De manera conceptual, fue Aristóteles quien dio origen a los estudios de la calidad desde la cualidad, por ser una de sus principales y primeras categorías de análisis para entender el mundo físico que nos circunda. La concibió - la cualidad - como aquello que nos permite diferenciar la sustancia de los objetos entre sí (lo que son en todos sus componentes con relación a los componentes de otros), de reconocerla, de describirla para comparar o incluso cualificar: "Llamo cualidad aquello en virtud de lo cual se dice que algunas cosas son calificadas de cierta manera” (Aristóteles, 1999, p. 74).

Por otro lado, al referirse ya no a los objetos como sí a los procesos inherentes a una actividad intelectual, y el periodismo es una de ellas, el asunto de la calidad es más complejo por las subjetividades y consideraciones que demanda a la hora de valorarse. Así, un sistema de información periodística para algunos puede ser de mayor calidad que otro gracias a la cobertura que ofrece o a la inclusión social que demanda. En tanto que para otros sectores estos parámetros no serían indicativos de una calidad, que 
más bien podría concentrarse en sus recursos tecnológicos o la lecturabilidad de los productos obtenidos.

Es la complejidad de cualificar respecto de la calidad de la actividad periodística. Por un lado, la de considerar la información periodística como un proceso susceptible de ser estudiado y valorado a través del análisis del producto publicado; por otro, la cualificación de la labor que centra su atención en la consecución de unos resultados reflejados no siempre en aspectos tan tangibles como sus logros propios de legitimidad y credibilidad social.

Observados en conjunto, son elementos que integran la calidad del trabajo a partir de la nitidez y estética de la imagen para el caso de un producto audiovisual, el volumen informativo de un periódico, la inmediatez de la emisión radial, la cobertura geográfica, los apoyos contextuales, entre otros, con la intención de configurar cierto tipo de valor informativo que para las empresas periodísticas y los gremios profesionales los lleva a reconsiderar su desempeño y los hace más competitivos unos frente a otros. ${ }^{12}$

De todas maneras, en todos los casos en los que se estudia la calidad informativa, se debe advertir sobre la denominada facticidad que acompaña a cualquier información, sea de naturaleza periodística, o no. El requisito para que un dato conserve su naturaleza informativa es que esté ligado en cualquier caso a una proposición con clara intención de verdad. En otras palabras, además de registrar los eventos que acaecen (lo verdaderamente ocurrido), deberá adicionar información relevante de quienes se vieron afectados, las circunstancias que rodearon los hechos, sus consecuencias, etc. ${ }^{13}$

12 Es de resaltar, en este sentido, el trabajo del equipo VAP-UC de la Facultad de Comunicaciones de la Pontificia Universidad Católica de Chile. El valor agregado periodístico (VAP) fue desarrollado como un instrumento para medir la calidad a partir de la relación de ciertos estándares fundados en valores y normas, los cuales tienen en cuenta determinadas variables fundamentales en dos momentos distintos del proceso informativo: la selección y la creación. El equipo logró identificar 50 variables para la prensa y 54 en la televisión (Pellegrini y Mujica, 2006).

$13 \mathrm{El}$ asunto fue expuesto dentro del propio Informe Hutchins en 1947. Aunque Robert M. Hutchins lo advertía en relación con la información internacional, resultaba válido para los casos de cubrimiento periodístico: "El primer requisito es que los medios de comunicación deben ser precisos. No deben mentir... Ya no basta con informar el hecho. Ahora es necesario informar sobre la verdad del hecho mismo" (Commission on Freedom of the Press, 1947, p. 22). 


\section{Otras concepciones sobre calidad informativa}

Se han dado ocasiones en las cuales el concepto de calidad informativa ha tenido otra acepción selectiva y ha sido aplicado sustancialmente al mundo de la prensa donde se la asimila a publicaciones de prestigio. Por ejemplo, John Merrill acunó la expresión diarios de calidad o de élite y José Vidal-Beneyto se refirió a los diarios de referencia dominante para describir un conjunto de medios que, a pesar de sus diferencias, poseían una característica común: tener como público a los dirigentes políticos, económicos y sociales de un país. Se daba por hecho que contar con una audiencia semejante implicaba contenidos con un alto nivel cualitativo (De Fontcuberta, 1999, p. 61).

El asunto se evidenció no solo en la prensa y los medios masivos de información. Terminada la Primera Guerra Mundial trascendió a otros niveles cuando Walter Lippmann sorprendía a sus compatriotas al resaltar la incompetencia del ciudadano mediocremente informado en un mundo cada vez más complejo de entender. En 1922, editó su texto Public opinion como resultado de su amarga experiencia tras el fracaso de la Conferencia de Paz en París: "Estereotipos y prejuicios configuran la realidad poblada de pseudo eventos que el público no acierta a distinguir. La teoría democrática del ciudadano que, bien informado, puede opinar con conocimiento de causas, resulta imposible" (Giner, 1987, p. 42).

Esta observación produjo, entonces, un fuerte debate intelectual con el filósofo John Dewey, quien, al contrario, creía en una prensa que pudiera presentar hechos inteligibles para la mayoría de los ciudadanos que, según él, debían mejorar las condiciones de la opinión pública sin interponer tecnócratas que mediaran en el proceso. Dewey parecía estar refiriéndose a la idea del pensamiento en voz alta como una forma característica del pensamiento de una sociedad liberal al escribir en su texto, La reconstrucción de la filosofía, que la prueba que sirve para decidir si un supuesto bien es auténtico o espurio nos la proporciona su capacidad para resistir la publicidad y la comunicación (Catalán, 2001, p. 142).

Con su idea del pensamiento en voz alta, Dewey, al igual que Kant, quiso darle una acepción profunda al concepto de opinión pública, para que 
en el mismo sentido se produjera entre la ciudadanía un pensamiento competente acerca de lo público por la posibilidad, precisamente, de ser conocido por todos:

Puede decirse, por tanto, que aquel poder exterior que arrebata a los hombres la libertad de comunicar públicamente sus pensamientos, les quita también la libertad de pensamiento: la única joya que aún nos queda junto a todas las demás cargas civiles y la única mediante la cual puede procurarse remedio a todos los males de ese estado. (Kant, 1999, p. 168)

Lippmann, al contrario, consideraba pertinente para mejorar el diálogo social entre ciudadanos y prensa, entre el mundo y su gente, según sus propias palabras, que los medios contaran con la presencia de expertos o insiders, como seres inteligentes que se comportaran como científicos sociales y políticos. Aún la discusión sigue vigente, y ambas posturas, en lugar de excluirse como en antaño, parecen complementarse en la medida en que se evalúa el papel del informador y su rol de intérprete de una realidad cada vez más compleja que exige la presencia en las empresas informativas de personas competentes dispuestas a entender el mundo con la mirada del experto y la voluntad, desinteresada en principio, del periodista para comunicarlo de forma entendible. ${ }^{14}$

\section{La calidad como transformación}

Como se advirtió desde el inicio, el asunto de la calidad se asume para este trabajo como transformación del acto informativo (búsqueda, elaboración y difusión de la información periodística) en relación con hechos de dolor y muerte. Es una transformación que resulta ligada, por acción de ella misma, a la noción de un valor agregado a lo que informa. La posibilidad de transformar este acto considerando ciertos valores morales en el momento de

14 A lo largo de este trabajo, se parte de la idea de considerar al periodista como un intérprete de la realidad del mundo que confronta a diario. Su trabajo va más allá de ser un simple testigo ocular, un relator o un mediador de historias, como se le ha considerado en múltiples ocasiones. Su compromiso profesional con el oficio se refleja, no solo por la fidelidad con que cuente sus historias, sino, además, por el conocimiento apropiado con que lo haga. Como cualquier buen intérprete, no solo debe reconocer de forma adecuada los códigos para comunicarlos adecuadamente, sino que debe, además, comprenderlos mejor que otros, porque los va a contar a la sociedad entera. 
llevarlo a cabo abre la posibilidad, desde el reportero, de imprimirle un mayor valor periodístico al producto obtenido. ${ }^{15}$

Esta transformación puede ser evidente si en su selección informativa, sobre hechos de dolor, tiene en cuenta determinados criterios, como el respeto, la solidaridad y la confianza frente al suceso por divulgar. Sin duda, el periodismo es un tipo de oficio que se lleva a cabo bajo ciertas particularidades. La mayoría de los reporteros se perfeccionan en el hacer y en el saber cómo hacer. ${ }^{16}$

Por tanto, la universidad cumple a cabalidad un papel al introducir a los estudiantes en las destrezas básicas y en generar un número limitado de oportunidades para practicarlas, en algunos cursos avanzados, a través de prácticas profesionales o escribiendo para periódicos estudiantiles. Sin embargo, y como cualquier oficio concebido en el hacer, muchas de sus acciones se perfeccionan y profesionalizan en el hacer, a la vez que son susceptibles de valoración ética, según se conozca la intención de sus actos, el resultado y las consecuencias que produzcan estas acciones (Awad, 2003, p. 9).

El reto para los profesionales de la prensa está, por tanto, en considerar un comportamiento ético mejor establecido (profesando ciertos valores), a pesar de las diferencias entre los escenarios y contextos a lo largo de las distintas culturas profesionales del ejercicio periodístico. Estas consideraciones o razones morales no toman en cuenta los intereses particulares de un individuo, un grupo limitado de personas, los integrantes de un gremio profesional o una corporación o empresa informativa determinada. Al contrario, presuponen la consideración de cualquier ser humano como un fin en sí mismo y no como un medio para la satisfacción de tales intereses particulares (Moya,1997). ${ }^{17}$

15 El término original de transformación pertenece a Harvey y Green (1993), citados por Sabatier de Cerioni (1999).

16 En este hacer y luego saber hacer, se intentará al final del texto proponer un cuadro ideal de rutinas que sintetizan en cierta medida la apuesta moral por mejorar la calidad de la información referida al dolor.

17 Aquellas consideraciones del tipo "no quiero hacer esto porque no me gustaría que a mí me lo hicieran" hacen parte de múltiples expresiones del llamado imperativo categórico de Immanuel Kant: "Obra sólo según una máxima tal que puedas querer al mismo tiempo que se torne ley universal” (Kant, 1999, p. 135). 
La construcción de una ética de orden global puede ir hacia delante explorando la posibilidad de principios universales que no solo permitan sino que también inviten al reconocimiento de la diferencia bajo una moral que se disponga hacia lo particular y lo universal a la vez.

Si se siguen caminos exploratorios hacia una ética global de medios, es posible de lograr si se considera además en varios niveles — presuposiciones, principios y preceptos - todo tipo de experiencias morales inmersas en una interacción dinámica y en medio de un escenario holístico, que trate complejas y profundas consideraciones del sentir humano.

Las presuposiciones, por ejemplo, de no violencia, búsqueda de la libertad, preservación de la dignidad humana o la defensa de la vida, son visiones del mundo a manera de giroscopio alrededor del cual se piensa y recompone la experiencia social, así como los compromisos adquiridos entre los hombres a manera de un eje común para el saber humano. Son visiones del mundo que dan significado a nuestra consciencia. Ellas representan un conjunto específico de creencias sobre el destino humano. En fin, es la condición específica de la teorización básica de la moral (Christians, Rao, Ward y Wasserman, 2008, p. 142).

\section{Razones del cubrimiento periodístico sobre el dolor}

Como se dijo antes, es de considerar que muchas valoraciones morales surgen en contextos diferentes que influyen finalmente en las decisiones de reporteros y editores a la hora de elaborar un producto informativo. Es una ética que se reconoce en medio de la disposición de múltiples maneras de concebir la cultura profesional del periodista dentro de una comunicación marcadamente humana.

Más allá de las situaciones descritas, los principios de respeto, solidaridad y confianza o razones morales como la verdad, si fuera el caso, son constitutivos generalmente de cualquier teoría ética viable, universal y adecuada, porque están inculcados en una humanidad que permite interpretar 
el conocimiento que se tiene del mundo real con estrategias reflexivas en concordancia con la etnografía y lo meramente conceptual, la cultura y la historia de mundos complejos que actúan, en últimas, como tipos de protonormas posibles en mundos diversos. ${ }^{18}$

La verdad es un principio rector del periodismo que, a pesar de las distintas y múltiples interpretaciones que de ella se tenga en el momento de informar, permite al menos acuerdos fundamentales en relación con su búsqueda. De nuevo, los principios regulativos, aunque imbuidos en la historia, finalmente implican una dimensión realista y moral a la vez en cada hombre (Christians, Rao, Ward y Wasserman, 2008, p. 143).

\section{El respeto para la información periodística ${ }^{19}$}

En el campo de la moral informativa, el valor del respeto le permite al reportero acceder a una mejor consciencia de sí mismo y al reconocimiento del rol social que desempeña por lo que hace y representa. Funda el respeto hacia la consciencia de su propia libertad y lo funda igualmente por los demás, en tanto que el otro como él mismo es una persona con derechos y reconocimientos. ${ }^{20}$

18 Desde Walter Lippmann (1889-1974), está claro que el periodismo no busca la verdad, porque lo que busca es la noticia, que, evidentemente, no es lo mismo, aunque, por definición, la noticia periodística deba ser verdadera; eso sí, con una exigencia atenuada por matices y licencias (De Aguinaga, 1998, p. 124).

19 En los griegos, el respeto era un valor del que todos debíamos tener el mayor cuidado, escrúpulo y consideración por lo que representa o refiere con relación a algo o alguien: se respeta una norma, un hombre, una institución, un rango, un dogma, una función y una creencia. Luego, Immanuel Kant le daría un giro importante al valor mismo, para referirlo, no solo al objeto que invita al respeto, sino al sujeto que se reconoce a sí mismo como instancia fundadora de dicho respeto. Para él, la misma capacidad de respetar se vuelve en su recurrencia objeto del mayor respeto y su práctica revela la dignidad del hombre. Las personas tienen una dignidad que, en el caso de su especie, se llamará humanidad. Como tal, algo objeto de respeto es algo que define toda facultad de actuar como nos parezca.

20 Así lo advierte Kant: "Pero aunque el respeto es, efectivamente, un sentimiento, no es un sentimiento recibido del exterior por medio de un influjo, sino espontáneamente autogenerado a través de un concepto de la razón y, por lo tanto, específicamente distinto de todos los sentimientos de la primera clase, que pueden reducirse a inclinación o miedo. Lo que yo reconozco inmediatamente para mí como una ley lo reconozco con respeto, y este respeto significa solamente la conciencia de la subordinación de mi voluntad a una ley, sin la mediación de otros influjos en mi sentir. La determinación inmediata de la voluntad por la ley y la conciencia de la misma se llama respeto, de manera que este es considerado efecto de la ley sobre el sujeto y no causa. Propiamente es respeto la representación de un valor que menoscaba el amor que me tengo a mí mismo" (1992, p. 6). 
Aunque en los términos de una ética informativa el periodista actúa en plena libertad como observador de la naturaleza, termina por desarrollar empatías o sentimientos de rechazo hacia objetos, hechos y personas. Por supuesto, el respeto le permite entender a la sociedad y su entorno en medio de virtudes y limitaciones. Si el producto periodístico logra discernir el umbral que no se debe atravesar a fin de mantener la distancia que amerite lo soportable para todos, posiblemente logre una mejor calidad informativa. ${ }^{21}$

El valor del respeto es igualmente fuente de deberes para cualquiera, en cuyo cumplimiento aparecen acciones precisas con un profundo sentido humano y, por omisión, formas hirientes de informar que trastocan otros sentimientos en situaciones de dolor y muerte.

No hay que perder de vista que frente a dichos eventos se hace necesario asignarles un rostro humano a los hechos objeto de la noticia. Así, se debe propender a visibilizar la situación de quienes están en condición de adversidad. En ocasiones, al describirse hechos o catástrofes naturales, la atención de las noticias se concentra en las consecuencias o dimensiones del evento acaecido y dejan a un lado a las propias víctimas como actores directos de los hechos que se describen. ${ }^{22}$

Una manera de mostrar respeto por quienes se ven involucrados en situaciones informativas difíciles es caracterizar los propios datos a partir de las personas involucradas más allá inclusive de la trascendencia informativa. Por la búsqueda de novedad que demandan las noticias, muchas veces se matizan los eventos a partir de los resultados de los hechos y no por lo que las víctimas representan para el resto de la comunidad.

21 La idea original corresponde a Immanuel Kant y se encuentra descrita en términos generales en relación con el cumplimiento de este valor por parte de cualquier hombre en Fundamentación de la metafísica de las costumbres.

22 A manera de ilustración, es pertinente traer a colación el manejo televisivo que se hizo de la serie de atentados a Francia en noviembre de 2015. La cobertura mediática fue duramente criticada por el grado de voyerismo y exhibicionismo que se dio en algunas cadenas, como Télévision française 1 y France 2, cuyas emisiones se acercaron a la espectacularidad de los medios informativos estadounidenses, donde la puesta en escena de imágenes violentas (sangre, balaceras y persecuciones) y de las emociones (lágrimas de parientes, angustia de transeúntes y recogimiento) realza a menudo el voyerismo y, sobre todo, eluden el análisis: el comentario de la acción prima por sobre la reflexión (Reymon, 2015). 


\section{La solidaridad como razón moral ${ }^{23}$}

Los formatos periodísticos que narran historias de víctimas o acontecimientos de dolor y muerte tienen la facultad de evidenciar ante la opinión pública, a partir de realidades informativas, escenarios que generalmente resultan excepcionales para la mayor cantidad de personas. En este sentido, esta coparticipación o intervención abierta y espontánea del público permite a unos y otros compartir sentimientos, alegrías, temores o frustraciones en torno a eventos difíciles de narrar por las circunstancias expuestas.

En el caso particular que aquí se anuncia, un valor como la solidaridad incidirá en la calidad del producto informativo en la medida en que, a través del desempeño del informador o las notas divulgadas más allá de la conmoción generada por el drama descrito, trascienda las propias visiones del suceso para ubicar a cualquier ciudadano, lector o a la audiencia misma en los "pies del otro". 24

Una manera de atender a esto es permitir que los detalles que configuran los hechos noticiosos deben relacionarse de manera estrecha con los derechos de los involucrados — sobre todo de las víctimas y sus familiares - por encima de las circunstancias acaecidas o la relevancia informativa expuesta. Desafortunadamente, no siempre resulta adecuada dicha relación, en parte, por falta de criterios más específicos para referirse a situaciones sensibles en medio de intereses particulares marcados por el ra-

23 Una aproximación general al concepto de solidaridad permite entenderlo como un valor que pertenece a una comunidad integrada por seres semejantes, quienes, bajo las diferencias que los caracterizan, cuentan con una identidad fundamental de seres humanos a la que se hace irrenunciable. Esta identidad genera un lazo mínimo y necesario de solidaridad entre cada individuo y el resto. De esta forma, y a lo largo del tiempo, han llegado a depender unos de otros de tal manera que la solidaridad se considera como un valor cobijado por un hecho natural de orden social en una comunidad. Se podrá afirmar así que la solidaridad es aquel reconocimiento de la humanidad que nos es común a todos los seres humanos, en particular a aquellos, otros, que se encuentran alejados de nuestra propia realidad.

24 En ocasiones, los grandes reporteros han advertido que el periodismo es, ante todo, un acto de servicio, es ponerse en el lugar de otro, comprender lo otro y, a veces, ser otro (Martínez, 2010). Por lo mismo, es importante diferenciar esta solidaridad de la compasión (conmiseración o lástima), porque puede ocurrir que, en lugar de expresarse un sentimiento de solidaridad, se termine por mostrar un torrente de dolor que arrastre a las víctimas a un espectáculo mediático que los afecte aún más o, en el peor de los casos, a un culpabilismo frustrante que termina por convocar a la audiencia misma a sentimientos de desesperanza por la inevitabilidad del no poder hacer nada ante la situación divulgada. 
ting, la exposición pública de los propios afectados, la naturaleza del espacio informativo u otros que inciden directamente en la calidad del programa.

Recordar el drama humano en torno al asesinato de una mujer luego de su participación en un reality show denominado El valor de la verdad, en el que, para continuar y ganar un dinero, se debió compartir detalles de la vida personal e íntima ilustra lo anterior. Su testimonio exhibido dentro de varios capítulos que tuvieron altísima audiencia por el estilo truculento del propio formato del concurso dejó absorto al público, precisamente, por las revelaciones hechas por la participante.

Luego del escándalo, las siguientes semanas, e incluso su propia muerte ocurrida unos meses después, se convirtió en un nuevo reality que se transmitió juiciosamente por la televisión peruana narrado en vivo y en directo entre los desaires del exnovio ofendido a la postre su asesino, la desazón de quien reveló detalles de su intimidad de manera pública o el dolor de sus padres al encontrar su cuerpo en medio de una inusual campaña mediática.

La crónica del asunto se cierra, finalmente, en un espacio de casi quince minutos que registra el momento exacto en que las autoridades confirman ante la teleaudiencia que, en efecto, es el cuerpo de Ruth Talía Sayas, quien por 15000 soles terminó involucrada en un show mediático que la condujo a la muerte sin consideración alguna en su dignidad como persona y mujer junto con el dolor de quienes la rodearon. ${ }^{25}$

Otra mirada sobre la solidaridad como valor informativo es la del filósofo Avishai Margalit, quien advierte que los hombres están obligados a recordar a las personas y los acontecimientos del pasado; por supuesto, dicho deber incluye a los medios de información que interpretan como tarea cotidiana la realidad circundante. En todo caso, el interés del ciudadano, puesto en el pasado, incrementa la sensación de pertenencia a un grupo, porque evidencia continuidad en el tiempo a través de los distintos recuerdos de otros que podrían ser como él.

25 Ver detalles de lo acontecido en el programa Día D, espacio periodístico dominical del canal de televisión ATV.pe en https://www.youtube.com/watch?v=DGfYegHoVlY 
En otras palabras, los recuerdos permiten generar mayores sentimientos de solidaridad bajo una especie de ética del recuerdo, que aleja a los ciudadanos del acostumbrado desinterés ante los temas pasados en el impetuoso mundo de la actualidad de las noticias. Frente a acontecimientos dramáticos, se toma consciencia de sus formas y modos a través del recuerdo compartido. La importancia que reviste el suceso dependerá de la medida en que se establezca una relación personal con este, por lo cual no solo se compartirá el recuerdo de lo sucedido, sino también el modo de transmisión (por cuenta de la prensa), precisamente como si fuese el acontecimiento mismo (Margalit, 2002, p. 45).

\section{La confianza en la información sobre el dolor ${ }^{26}$}

En general, hacia la prensa, la confianza se manifiesta por la credibilidad en los procedimientos para la obtención de sus datos, la precisión de los informes, la exactitud en los análisis, la veracidad de las afirmaciones, en fin, por el rigor con que se informa en el momento de articular informativamente la compleja realidad del mundo físico y social.

Es un tipo de valor informativo que va más allá de la tensión novedad frente a cambio, que representa la noticia generalmente dentro de los criterios regulares de noticiabilidad, con la intención de lograr un pacto más estable entre reporteros, medios de información y ciudadanos. Entendida así la confianza, supone, entonces, un acuerdo, en ocasiones de orden moral, entre los integrantes de una comunidad de actores que se interrelacionan para hacer posible la producción de noticias de forma institucionalizada mediante empresas, clubes de suscriptores o agencias de noticias.

26 La confianza es un valor esencial en las relaciones de las personas. Sin ella, probablemente serían recurrentes las rencillas de diversa índole entre los individuos que integran un grupo social e interactúan por acuerdos generalmente basados en la mutua confianza. En un amplio sentido, es un hecho básico de la vida social. Por supuesto que, en determinadas situaciones, el hombre puede decidir si otorga confianza o no, aunque una completa ausencia de confianza le impediría, incluso, levantarse en la mañana. Sería víctima de un sentido vago de miedo y de temores paralizantes. No sería capaz de formular una desconfianza definitiva y hacer de ello un fundamento para medidas preventivas, ya que esto presupondría confianza en otras direcciones. Cualquier cosa y todo sería posible en su vida (Luhmann, 2005, p. 5). 
Este es quizá uno de los valores procedimentales más importantes en la vida del reportero. Su responsabilidad por aquello de lo que informa, la legitimidad social obtenida y, por supuesto, su credibilidad serán pilares de la labor profesional que conlleva como trasfondo, precisamente, la confianza.

Informar no basta menos cuando se trata de hechos de dolor. Un lector necesita algo más que las versiones contrapuestas de las partes en la consabida neutralidad informativa. Requiere más que la exhaustiva descripción de los actos. Y aunque el periodista es depositario del derecho a la información y, como tal, tiene el deber de informar, debe en igual sentido descifrar la verdad y no contentarse con reflejar lo que se dice, por mucha precisión y textualidad con que se transmita (Giner, 1987, p. 43).

De ahí que la confianza invite de igual manera a promover y sostener en las empresas informativas espacios institucionalizados, como consejos de lectores que actúen en forma de veedores de las noticias emitidas y discutir, de ser posible, con reporteros y editores sobre la calidad de las noticias, en particular aquellas asociadas a hechos más sensibles (vida íntima, muertes trágicas, derechos de género, sexualidad, corrupción, entre otros asuntos).

Cuando los medios de información atienden los requerimientos sociales de sus públicos para afianzar lazos de confianza, las situaciones complejas serán tratadas con mayor cuidado y discreción. De ahí pueden resultar mejores propuestas, enfoques distintos, secciones informativas especializadas que garanticen, en todo caso, una discusión amplia y sostenida, segura y confiable para el público, como eje de una difusión informativa que capte un mayor interés ciudadano.

Según El Nuevo Herald, en un estudio realizado a comienzos de 2016 a lo largo de los Estados Unidos, la confianza en los medios de comunicación se ha visto erosionada por las percepciones de imprecisión y sesgo, alimentadas, en parte, por el escepticismo de los ciudadanos sobre lo que leen en las redes sociales. Solo $6 \%$ de las personas dice tener mucha confianza en los medios de comunicación y pone a la industria de las noticias más o menos al nivel del Congreso, pero muy debajo de otras instituciones. Casi $90 \%$ de los estadounidenses dice que es extremadamente o muy importante que los 
medios de comunicación reflejen los hechos de forma correcta, de acuerdo con el estudio. Casi 4 de cada 10 afirma que puede recordar un incidente específico que mermó su confianza en los medios de prensa, más frecuente que con la precisión o la percepción de que es tendencioso (Feldman y Swanson, 2016).

Insistir sobre la confianza como razón moral en el cubrimiento de hechos de dolor y muerte, no solo pone en consideración los diversos mecanismos de participación ciudadana — cartas recibidas, foros virtuales, correos electrónicos, participación de redes sociales - en las decisiones editoriales más importantes de las empresas informativas, sino que, además, debe ser acompañada de la difusión clara de su identidad — como medio de comunicación e información- para generarla.

Se evitarán, entonces, suspicacias sociales sobre lo que hacen profesionalmente en el momento de informar y con seguridad mejorará el reconocimiento público de sus reporteros, el rol de quienes deben estar al frente de la entidad empresarial y, por supuesto, el cumplimiento de los principios éticos establecidos en sus códigos profesionales. ${ }^{27}$

La tabla 1 sintetiza las consideraciones morales tenidas en cuenta bajo la figura de los tres valores propuestos: respeto, solidaridad y confianza por tener en cuenta en las distintas fases de elaboración - recopilación, procesamiento y difusión- de los datos de interés informativo para dos grandes escenarios que encierra la mayoría de los hechos que aquí interesan: las tragedias naturales de cualquier índole (terremotos, inundaciones y catástrofes) y los actos humanos de consecuencias funestas (homicidios, actos de terrorismo, barbarie indiscriminada, afrentas contra grupos humanos, suicidios, entre otros).

27 Resultan pertinentes, a propósito de lo anotado, las palabras de la fundadora de The Huffington Post, Arianna Huffington, al responder una pregunta de uno de los alumnos del máster que el periódico El País dirige, durante un encuentro en 2011: "Si cualquiera puede escribir y publicar un blog con su propia información, ¿qué valor añadido puede dar un periodista?”, a lo que responde: “La confianza es la clave diferenciadora. Puedes tener a miles de personas con una plataforma alimentándola ahora a través de Twitter, Facebook o subiendo un video, pero la cuestión es ¿quién es fiable? La confianza es la mayor calidad y esa es la razón de que seamos una organización mediática o no” (https://goo.gl/2wa9ys) 
Un aspecto relevante anotado atrás para tener en cuenta es el referido al hacer (zona sin sombrear) sobre el saber hacer (zona sombreada) para obtener un proceso de transformación hacia una mayor calidad informativa en relación con hechos de dolor y muerte bajo una concepción de orden ético-moral, de ahí que no se hagan consideraciones para cada valor propuesto por aparte, sino que los tres se consideren —en simultáneo- para cada una de las fases del trabajo informativo.

\section{Tabla 1. Fases de selección, procesamiento y difusión en torno a noticias sobre dolor y muerte}

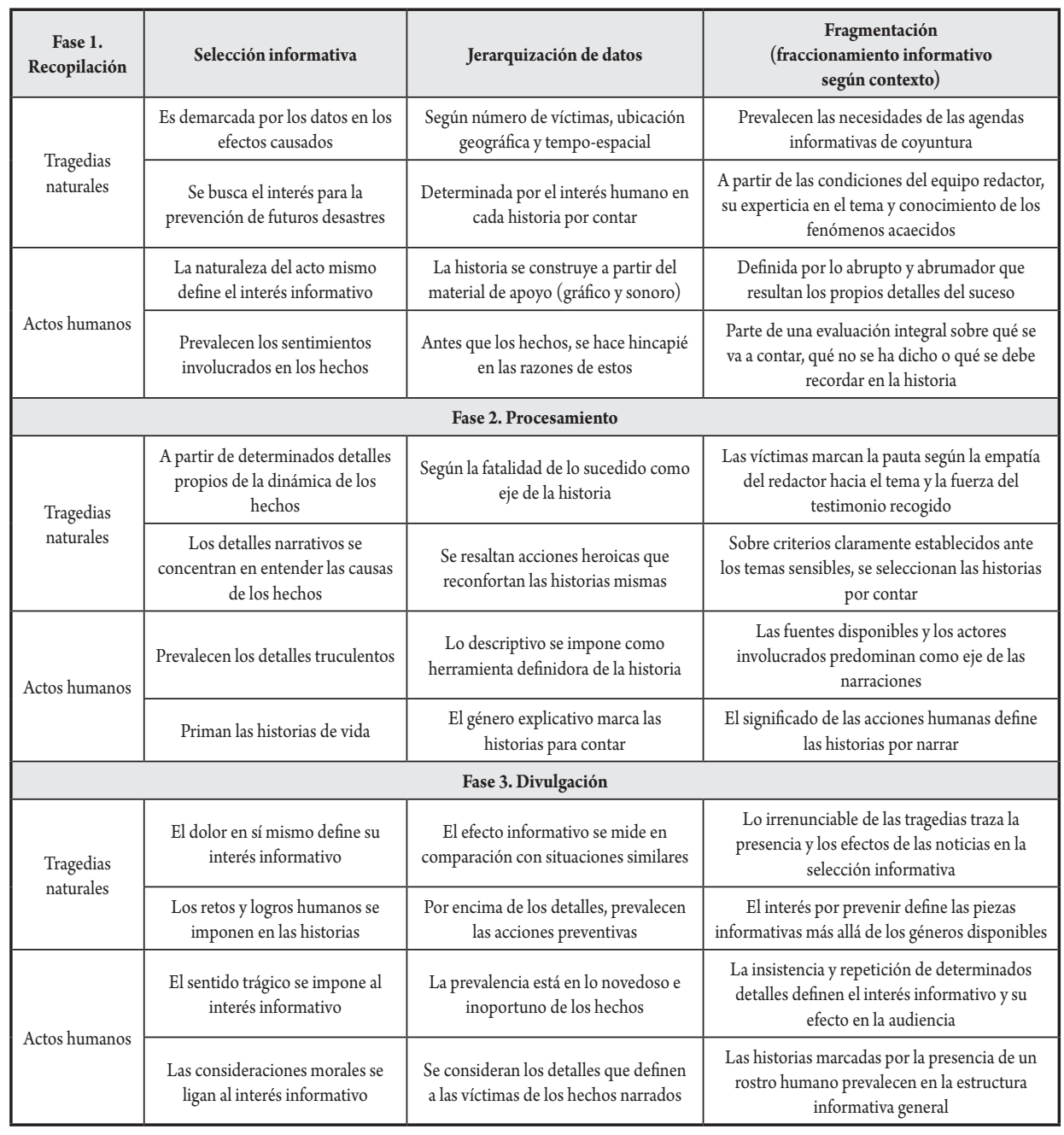

Fuente: Elaboración propia. 


\section{Y, finalmente, ¿cuál es la apuesta moral?}

Como anotábamos al inicio del texto, informar a la sociedad sobre hechos de dolor bajo cualquier dimensión física y moral o tratar el asunto de la muerte en especial en ciertas circunstancias será siempre un asunto importante tanto para quien lo padece como para quien requiere tratar sobre ello por razones del oficio, como ocurre con los periodistas.

Hacerlo bajo las debidas consideraciones humanas no solo será un asunto de carácter ético y moral, sino de interés académico, porque contiene una serie de interrogantes de gran calado para entender la compleja realidad de la práctica y de la concepción de la labor periodística configuradora de la cultura profesional de un grupo de reporteros que integran esta comunidad interpretativa de la realidad de lo que acontece, en particular, cuando se dan hechos violentos.

Nuestra apuesta está dirigida a considerar que es posible — desde una lectura moral de los hechos y las circunstancias que rodean los acontecimientos de sufrimiento humano - transformar las prácticas profesionales en el manejo informativo en favor de una mayor calidad, que, aunque no sea la única por considerar, induce a un interés y una atención de la prensa en torno a unos valores que se pueden considerar cuando se tratan periodísticamente determinados asuntos sensibles para la opinión pública.

En este sentido, se deja claramente expuesta la necesidad e importancia de las razones morales en la deliberación práctica del periodista o el reportero al enfrentarse a determinadas situaciones, producto de hechos que causan formas distintas de dolor en la sociedad.

Los profesionales de la información periodística poseen rutinas previstas para el cubrimiento de las noticias. Estos procedimientos no varían en esencia dentro de esta comunidad e incluso trascienden fronteras y contextos políticos y culturales. Sin embargo, cuando un reportero en uso de su libertad y responsabilidad previene además otras razones — las morales para nuestro caso - en la elaboración de esta información, aparecen otras consideraciones de orden humano, dirigidas a quienes padecen de forma 
directa o indirecta algún tipo de dolor, con la estima que se merecen como fin de la noticia misma y no como medio para difundirla por el interés que representa para el público.

Por supuesto, no es la última palabra al respecto. Al contrario, cada día prevalece una mayor inquietud e interés social por entender un fenómeno como el dolor y su difusión a través de los medios de comunicación, que se hace palpable a la humanidad y se ha articulado en múltiples representaciones culturales, reiteraciones mediáticas y narrativas en las ciencias sociales, el arte, la filosofía, la ciencia, la política o la religión.

Sin embargo, es, precisamente, en los medios de comunicación e información donde se fijan mayormente las miradas críticas por lo que ocurre con lo que algunos autores denominan la trivialización o banalización del mal, al observar cómo aquellas historias truculentas que abundan en las noticias diarias se transforman en meros objetos de consumo masivo de gran efecto mediático, que han logrado que las audiencias ahora mismo consuman más dolor, aunque estemos menos preparados para soportarlo por su incomprensibilidad y dificultad para aceptarlo.

Es, sin duda, una profunda contradicción emocional e incluso moral de la sociedad que pone en entredicho el papel de la prensa en las sociedades modernas, la de darle sentido social al presente, al señalarla de irresponsable al cubrir tragedias y desgracias que agobian a la humanidad en eventos inexcusables de interés público, que deben ser informados bajo la presión de la inmediatez y el presentismo que se impone en las rutinas periodísticas y en la dinámica competitiva de las empresas informativas.

Por lo expuesto aquí, se consideró además —el hacer y el saber hacer- periodísticos como acciones fundadas en la razón, pero antecedidas por muchas consideraciones morales que de manera intensionada buscan transformar las prácticas que regularmente se tienen para lograr una mayor calidad en el momento de emitir esta información periodística.

Hay que insistir de nuevo en que el respeto, la solidaridad y la confianza no son los únicos valores para obtener una mejoría en el trabajo por 
cuenta del reportero ni la única manera de alcanzar su calidad. Pero, puestos de una manera casi holística bajo un esquema específico, evidencian, no solo la dinámica de una tarea comprometida al informar con el sufrimiento humano, sino también con la posibilidad de un cambio, de una mejoría o, como se ha denominado aquí, de una transformación, a pesar de los desatinos y aciertos que se dan en el día a día de la información periodística.

En una columna de opinión a comienzos de 2015, el periodista español Miguel Ángel Bastenier resaltaba los retos de la prensa global en procesos de conflicto o búsqueda de la paz.

Para él, siempre es posible hacer daño, aunque se adopten todas las precauciones del caso. Si alguien es acusado de hacer cosas terribles, según pruebas que las autoridades dicen tener, la prensa informará sobre ello. Pero si, posteriormente, se demuestra su inocencia, por mucho que se publiquen versiones exculpatorias, el mal ya está hecho y la prensa será la única responsable ante la mirada de la opinión pública.

Por eso, resalta, el periodismo no es por todo ello una profesión para hacer amigos, sino para estigmatizar enemigos, con todos los riesgos inherentes que esto conlleva. ¿Será, entonces, relevante conservar ciertos principios morales que al menos aminoren los efectos de informar y consoliden en cierta medida la calidad informativa para un mundo tan complejo y cambiante como el que ahora mismo vivimos? (Bastenier, 2015).

\section{Referencias}

Aranguren, J. (2002). Diversos sentidos de la palabra dolor. ESE: Estudios sobre Educación, 2, III-I27.

Aristóteles (1971). El libro de las categorías. Buenos Aires: Aguilar.

Awad C., I. (2003). Hay que desmitificar el periodismo: entrevista con Ted Glasser. Revista Iberoamericana de Comunicación, 4, 81-95. 
Bastenier, M. A. (27 marzo 2015). El periodismo, la pazy la guerra. En El País. Recuperado de http://cultura.elpais.com/cultura/2015/03/27/ actualidad/1427487367_108230.html

Binder, D. (1994). Anatomy of a massacre. Foreign Policy, 97, 70-78.

Carlin, J. (10 mayo 2009). El momento crucial. En El País. Recuperado de http://elpais.com/diario/2009/05/10/domingo/1241927553_850215.html

Catalán, M. (2001). La libertad de la opinión en tiempos de guerra. Comunicación y Estudios Universitarios, 141-146.

Christians, C. G., Rao, S., Ward, S. J. y Wasserman, H. (2008). Toward a global media ethics: Theoretical perspectives. Ecquid Novi, 29(2), 135-172.

Commission on Freedom of the Press (1947). A free and responsible press. Illinois: University of Chicago.

De Aguinaga, E. (1998). ¿Información veraz? Estudios sobre el Mensaje Periodístico, 4, 123-134.

De Fontcuberta, M. (1999). Pauta y calidad informativa. Cuadernos.info, $13,61-69$.

El País (15 octubre 2011). Arianna Huffington destaca la confianza del lector como valor del blog. Recuperado de http://sociedad.elpais. com/sociedad/2011/10/15/videos/1318629603_870215.html

Feldman, C. y Swanson, E. (2016). Disminuye la confianza del público en medios de prensa. En Elnuevoherald.com. Recuperado http://www.elnuevoherald.com/noticias/estados-unidos/article72390557.html

Galdón López, G. (2001). Información, desinformación y manipulación. En G. Galdón López (coord.), Introducción a la comunicación y a la información (pp. 47-75). Barcelona: Ariel. 
Giner, J. A. (1987). La crisis de credibilidad de los informadores. En C. Soria (ed.), Prensa, paz, violencia y terrorismo: la crisis de credibilidad de los informadores (2.a ed., pp. 79-128). Pamplona: Eunsa.

Hanitzsch, T. (2007). Deconstructing journalism culture: Toward a universal theory. Communication Theory, 17(4), 367-385.

Harvey, L. y Green, D. (1993). Defining quality. Assessment \& Evaluation in Higher Education, 18(1), 9-34.

Herrera Damas, S. (2003). La participación del público en los medios: análisis crítico e intentos de solución. Comunicación y Sociedad, 26(1), 57-94.

Johnson, P. (1985). Fleet Street's Black Hole. The Spectator, p. 18.

Kant, I. (1999a). Fundamentación de la metafísica de las costumbres (trad. J. Mardomingo). Barcelona: Ariel.

Kant, I. (1999b). ¿Qué significa orientarse en el pensamiento? En En defensa de la Ilustración. Barcelona: Alba.

La vida y muerte de Ruth Thalía Sayas. Recuperado de https://www.youtube.com/watch?v=DGf YegHoVlY

Lecaros, M. J. (2014). Contenido y conclusiones de la Comisión Hutchins. Cuadernos.info, 1, 91-103.

López Mañero, C. (1997). Criterios deontológicos en el tratamiento informativo del dolor. Comunicación y Sociedad, 10(2), 125-161.

Luhmann, N. (2005). Confianza. Barcelona: Anthropos.

Margalit, A. (2002). Ética del recuerdo: lecciones Max Horkheimer. Barcelona: Herder. 
Martínez, T. E. (6 febrero 2010). Los hechos de la vida. En El Clarín. Recuperado de http://www.lanacion.com.ar/1228740-los-hechosde-la-vida

Mccombs, M. (2008). Lo que el público necesita saber. Documento de trabajo.

Mestre, A. (2008). La ética de la responsabilidad según Robert Spaemann. Recuperado de http://www.dspace.ups.edu.ec/handle/123456789/8246

Moreno Garrido, B. y Rueda Laffond, J. C. (2012). Televisión y memorias de la violencia. Hispania Nova: Revista de Historia Contemporánea, 10. Recuperado de https://dialnet.unirioja.es/servlet/ articulo? codigo $=3881094$

Moya, C. J. (1997). Libertad, responsabilidad y razones morales. Isegoría, $17,59-71$.

Pérez Gutiérrez, M. (2000). Acotación y caracterización del objeto de estudio. En El fenómeno de la información: una aproximación conceptual al flujo informativo. Madrid: Trotta.

Randall, D. (1999). El valor informativo. En El periodista universal (pp. 2536). Madrid: Siglo XXI.

Rawls, J. (1995). Teoría de la justicia (2. ${ }^{\mathrm{a}}$ ed.). México: Fondo de Cultura Económica.

Reymond, M. (19 noviembre 2015). La couverture des attentats dans les journaux télévisés: compassion ou voyeurisme? En Acrimed.org. Recuperado de http://www.acrimed.org/La-couverture-des-attentats-dans-les-journaux-televises-compassion-ou

Sabatier de Cerioni, M. A. (comp.) (1999). Evaluación institucional y acreditación. Santa Fe, Argentina: Universidad Nacional del Litoral. 
Sontag, S. (2003). Ante el dolor de los demás (trad. A. Major). Madrid: Alfaguara.

Soria, C. (1987). El secuestro terrorista de los medios de información. En C. Soria (ed.), Prensa, paz, violencia y terrorismo: la crisis de credibilidad de los informadores (pp. 31-37). Pamplona: Eunsa.

Soria, C. (2008). Una posible respuesta de las facultades de Comunicación ante la crisis y la revolución actual de los medios. Revista de Comunicación Universidad de Piura, 7, 182-198.

Traquina, N. (2013). Ser ou nao ser jornalista. En Teorías do jornalismo (vol. 2, pp. 31-58). Florianópolis: Editora Insular, Universidade Federal de Santa Catarina.

Universidad del Rosario (1999). Elementos de calidad en la Escuela de Ciencias Humanas. Documento de trabajo.

Weller, G. (1945). A Nagasaki Report. En Nuclearfiles.org. Recuperado de http://www.nuclearfiles.org/menu/key-issues/nuclear-weapons/history/pre-cold-war/hiroshima-nagasaki/weller_nagasaki-report.htm 